\title{
Henoch-Schönlein purpura with c-ANCA antibody in an adult ${ }^{*}$
}

\author{
Pedro de Freitas Silva Torraca ${ }^{1}$ \\ Günter Hans Filho ${ }^{1}$
}

\author{
Bruna Corrêa de Castro ${ }^{1}$
}

DOI: http://dx.doi.org/10.1590/abd1806-4841.20164181

\begin{abstract}
The Henoch-Schönlein purpura is the vasculitis associated with deposits of immunoglobulin A in small vessels. Its association with cytoplasmic antineutrophil cytoplasmic antibodies is possible, but rare. This vasculitis is uncommon in adults and the main clinic manifestations are purpuric lesions in lower limbs with gastrointestinal symptoms and renal involvement. The present work describes a rare case of Henoch-Schönlein purpura in an adult with cytoplasmic antineutrophil cytoplasmic antibodies.
\end{abstract}

Keywords: Antibodies, antineutrophil cytoplasmic; Purpura, Schoenlein-Henoch; Vasculitis

\section{INTRODUCTION}

Henoch-Schönlein purpura (HSP), purpura rheumatica or anaphylactoid purpura, currently named IgA vasculitis, is a systemic vasculitis of small vessels, mediated by immunocomplexes. ${ }^{1}$ Although it typically affects children, there are reports of onset in adults. ${ }^{2}$ Classically, the clinical picture is characterized by skin involvement (palpable purpura or petechial lesions in $100 \%$ of cases), arthralgia, abdominal pain and nephropathy. ${ }^{3,4}$ Histopathology of skin demonstrates leukocytoclastic vasculitis associated with deposition of IgA on vessels. ${ }^{5}$ As opposed to other vasculitides, such as granulomatous polyangiitis (Wegener's), microscopic polyangiitis and Churg-Strauss syndrome, positive markers for c-ANCA, class of cytoplasmic antineutrophil cytoplasmic antibodies, are rarely found in HSP. ${ }^{6,7}$

\section{CASE REPORT}

Male patient, 22 years old, complained about skin lesions, abdominal pain and polyarthralgia for the previous three days, after using a high-protein food supplement. At the dermatological examination, papular and macular erythematous-purpuric lesions and some target lesions with hemorrhagic-content bullae, located on the extensor surface of the upper limbs, on the back, buttocks and lower limbs in a symmetric fashion were observed (Figure 1, 2 and 3). At the physical examination, edema was noticed in the knees, elbows and shoulders.

Laboratory tests showed normocytic and normochromic anemia, creatinine $3.50 \mathrm{mg} / \mathrm{dl}$, TMSI with microscopic hematuria, proteinuria of $3.18 \mathrm{~g}$ per 24 hours, complement consumption, increased polyclonal gamma globulins, besides c-ANCA positivity with titers of 1:640 in two samples. Markers for hepatic function and lesion did not exhibit changes, serologies for hepatitis, syphilis and HIV were negative, tests for p-ANCA and ANF were non-reagent, coagulogram and $\mathrm{x}$-ray of thorax and sinuses were normal.

Histopathology of skin revealed fibrinoid necrosis and neutrophilic infiltrate with leukocytoclasia in small vessels of the superficial dermis (Figure 4). Direct immunofluorescence revealed granular deposits of IgA in the walls of vessels in the papillary and middle dermis (Figure 5). Treatment was done with prednisone (1 $\mathrm{mg} / \mathrm{kg} /$ day) and cyclophosphamide (20 mg/ kg, single dose).

\section{DISCUSSION}

HSP is a neutrophilic vasculitis of small vessels, resulting from intravascular deposition of IgA complexes. ${ }^{1}$ It is the most common vasculitis in children, affecting preferably males, with an incidence peak between 2 and 11 years of age (75\% of the cases) and self-limited course most of the times. ${ }^{2}$ It is characterized by the presence of the tetrad formed by non-thrombocytopenic palpable purpura, arthralgia, abdominal pain and renal changes. ${ }^{2,6}$

More than $90 \%$ of the reported HSP cases occurred in individuals up to 12 years old. 4 Although rare, cases in adults have already been described in a worldwide incidence varying from $3 .{ }^{4}$

Received on 03.11.2014

Approved by the Advisory Board and accepted for publication on 25.02.2015.

* Work performed at Hospital Universitário Maria Aparecida Pedrossian, of Universidade Federal de Mato Grosso do Sul (Humap-UFMS) - Campo Grande (MS), Brazil.

Financial Support: None.

Conflict of Interest: None.

1 Universidade Federal de Mato Grosso do Sul (UFMS) - Campo Grande (MS), Brazil.

(C2016 by Anais Brasileiros de Dermatologia 


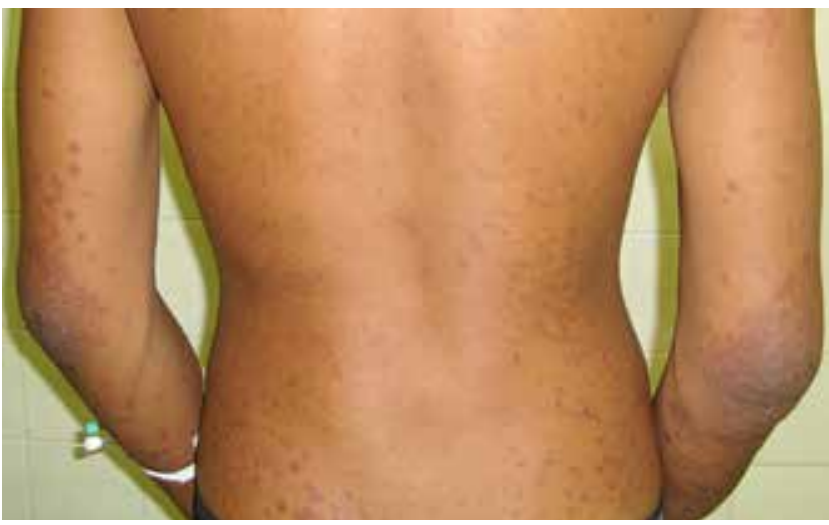

Figure 1: Papular and erythematous-purpuric lesions on the back and upper limbs

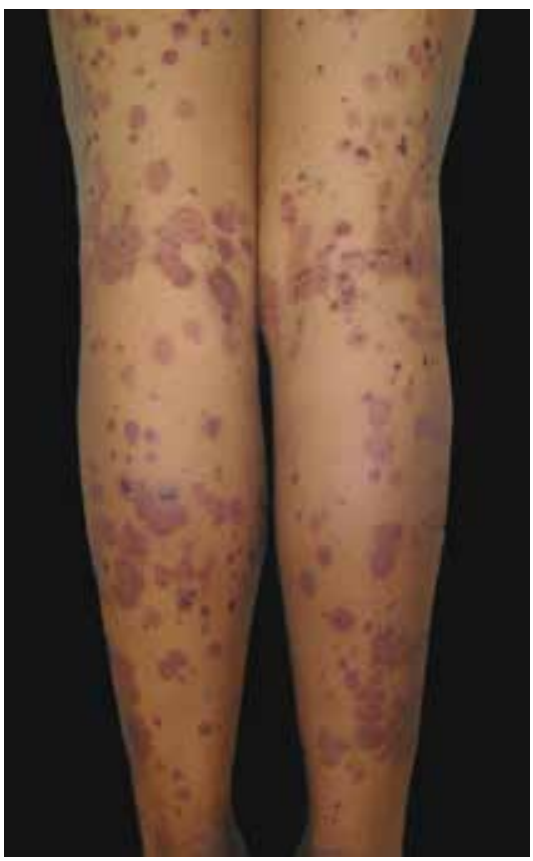

Figure 2:

Erythematous-purpuric macules and papules in the posterior region of lower limbs, besides target lesions and hemorrhagic bullae

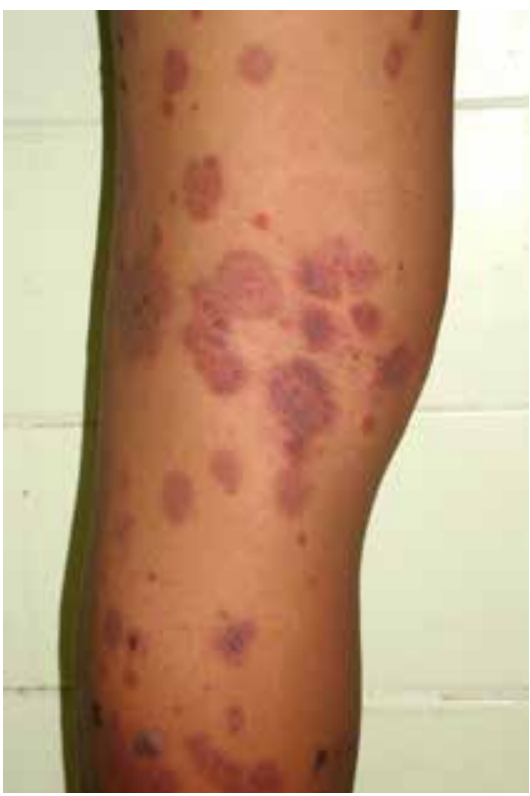

Figure 3:

Detail of lesions on lower limb

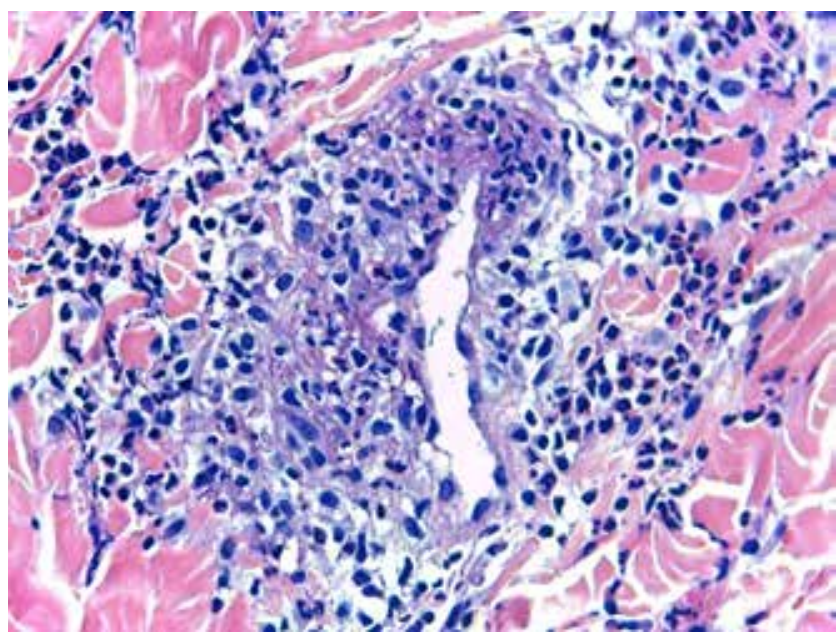

FIGURE 4: Histological examination of skin demonstrating fibrinoid necrosis and neutrophilic infiltrate with leukocytoclasia in small vessels of superficial dermis (HE, 100x)

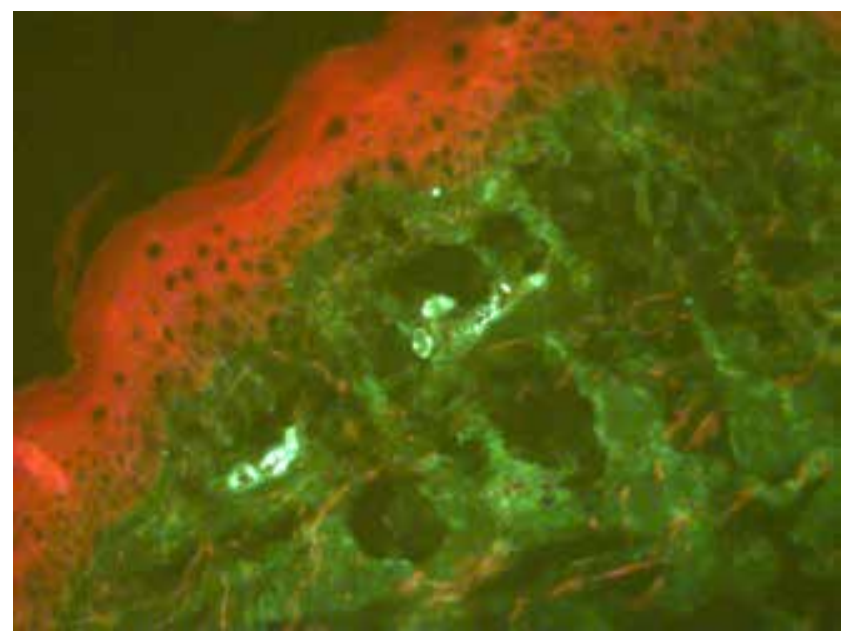

FIgURE 5: Granular deposits of IgA in vessels of superficial dermis under direct immunofluorescence

and 14.3 cases per 1 million inhabitants..$^{2,6,7}$ HSP typically appears after an acute infectious event, but may arise from direct contact with chemical products or food allergens, such as milk or gluten proteins. ${ }^{3,4}$

Diagnostic criteria for HSP include palpable purpura on lower limbs as a mandatory criterion and the presence of at least one of the following lesser criteria: diffuse abdominal pain, arthritis or arthralgia, hematuria or proteinuria and vascular deposits of $\operatorname{IgA}$, revealed by direct immunofluorescence. ${ }^{2}$ These deposits are responsible for renal changes, initially with pure mesangial proliferative glomerulonephritis and later evolving to membranoproliferative glomerulonephritis and renal failure. ${ }^{8,9}$ In histopathology, we observed leukocytoclastic vasculitis of arterioles and venules of affected sites. ${ }^{8}$ Although typical target lesions suggest the diagnosis of multiform erythema, clinical-laboratorial findings help in diagnostic definition. ${ }^{3,4}$

Among the main differential diagnoses of HSP are multiform erythema and granulomatosis with polyangiitis. Even though 
clinically similar in some cases, HSP originally does not present a profile of neutrophil cytoplasmic antibodies, like in granulomatosis with polyangiitis, or Wegener's granulomatosis. ${ }^{4,6,7,10}$ These antibodies are associated with necrotizing vasculitides and are classified according to its target antigen in two patterns: the specific pattern for myeloperoxidase (MPO-ANCA) of perinuclear presentation (p-ANCA), and the specific standard for proteinase 3 (PR3-ANCA), of cytoplasmic presentation (c-ANCA). ${ }^{1,6,7}$ Commonly the c-ANCA antibody is an IgG immunoglobulin, but it may be of type IgA or IgM. ${ }^{6}$ The lack of involvement of the respiratory tract and evidence of granulomatous infiltration - characteristic presentations of necrotizing vasculitides - reinforces the diagnosis of HSP with positive c-ANCA. ${ }^{1,5,6}$

Even with self-limiting symptoms most of the times, some cases of HSP require drug treatment. ${ }^{2}$ This recommendation depends mainly on the presence of renal involvement, because $5 \%$ of nephropathies are severe and may progress to renal failure. Some

\section{REFERENCES}

1. Jennette JC, Falk RJ, Bacon PA, Basu N, Cid MC, Ferrario F, et al. 2012 Revised International Chapel Hill Consensus Conference Nomenclature of Vasculitides. Arthritis Rheum. 2013;65:1-11.

2. Jithpratuck W, Elshenawy Y, Saleh H, Youngberg G, Chi DS, Krishnaswamy G. The clinical implications of adult-onset Henoch-Schoenlein purpura. Clin Mol Allergy. 2011;9:9.

3. Brandt H, Arnone M, Valente N, Sotto M, Criado P. Vasculite cutânea de pequenos vasos: subtipos e tratamento - Parte I. An Bras Dermatol. 2007;82:387-406.

4. Brandt H, Arnone M, Valente N, Sotto M, Criado P. Vasculite cutânea de pequenos vasos: subtipos e tratamento - Parte II. An Bras Dermatol. 2007;82:499-511.

5. Alfredo CS, Nunes NA, Len CA, Barbosa CM, Terreri MT, Hilário MO. HenochSchönlein purpura: recurrence and chronicity. J Pediatr (Rio J). 2007;83:177-80.

6. Boulis E, Majithia V, McMurray R. Adult-onset Henoch-Schonlein purpura with positive C-ANCA (anti-proteinase 3): Case report and review of literature. Rheumatol Int. 2013;33:493-6.

7. Kim JE, Shin Jl. Positive C-ANCA in Henoch-Schonlein purpura: what is the mechanism? Comment on: Adult-onset Henoch-Schonlein purpura with positive c-ANCA (anti-proteinase 3): case report and review of literature Rheumatol Int. 2014;34:1017.

8. de Almeida JL, Campos LM, Paim LB, Leone C, Koch VH, Silva CA. Renal involvement in Henoch-Schönlein purpura: a multivariate analysis of initial prognostic factors. J Pediatr (Rio J). 2007;83:259-66.

9. Jennette JC. IgA Nephropathy and IgA Vasculitis (Henoch-Schönlein Purpura). In: Fogo AB, Cohen AH, Colvin RB, Jennette JC, Alpers CE, editors. Fundamentals of Renal Pathology. New Yok: Springer Berlin Heidelberg; 2014. p.69-78.

10. Zhang Y, Wu YK, Ciorba MA, Ouyang Q. Significance of antineutrophil cytoplasmic antibody in adult patients with Henoch-Schönlein purpura presenting mainly with gastrointestinal symptoms. World J Gastroenterol. 2008;14:622-6. reports link c-ANCA positivity with fulminating nephropathy by deposits of IgA in a limited renal form of HSP., ${ }^{6,910}$ Therefore, this association may require more aggressive therapeutic measures, with the use of immunosuppressors. Corticosteroids are indicated when development of glomerulonephritis is suspected or when there is abdominal pain or intense arthralgia. ${ }^{2-4}$ The association of corticosteroids with azathioprine is indicated for treatment of glomerulonephritis already in course, and the association of corticosteroid with cyclophosphamide is considered in rapidly progressive glomerulonephritis. Colchicine may be used to control extensive skin lesions. For cases that are refractory to immunosuppressive treatment, the use of intravenous immunoglobulin is an alternative. ${ }^{2}$

From 2013, the American College of Rheumatology, the American Society of Nephrology and the European League Against Rheumatism (EULAR) renamed HSP as IgA Vasculitis, taking into consideration the deposits of immunoglobulin on small vessels, observed in the pathogenesis of vasculitis. ${ }^{1}$

\author{
MAILING ADDRESS: \\ Pedro de Freitas Silva Torraca \\ Av. Senador Filinto Müller, 1 \\ Pioneiros \\ 79080-190 - Campo Grande - MS \\ Brazil \\ E-mail:pftorraca@gmail.com
}

How to cite this article: Torraca PFS, Castro BC, Hans Filho G. Henoch-Schönlein purpura with c-ANCA antibody in adult. An Bras Dermatol. 2016;91(5):667-9. 